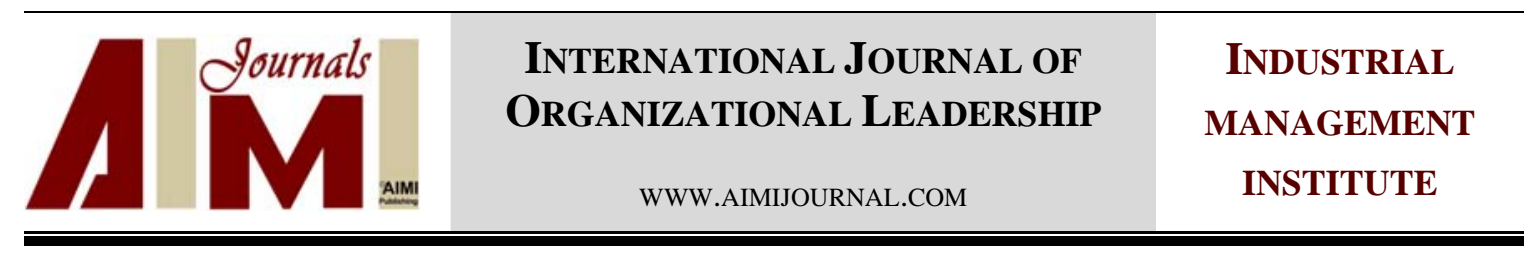

\title{
Identifying and Prioritizing Key Factors in Implementing Sammed in Zahedan
}

\author{
Bagher Kord $^{1}$, Elaheh Mirinejad ${ }^{2}$, Shirvan Keivani ${ }^{3}$, Hamed Kord ${ }^{4}$ \\ ${ }^{1}$ University of Sistan and Baluchestan, Zahedan, Iran \\ ${ }^{2}$ Zahedan University of Medical Sciences, Zahedan, Iran \\ ${ }^{3}$ Master of Business Management, Urmia, Iran \\ ${ }^{4}$ University of Velayat Iranshahr, Iranshahr, Iran
}

\begin{abstract}
Keywords:

E-government,

Prioritization, Sammed Plan

Correspondence:

mirinezhadelahe@yahoo.com

The identification of key factors in Sammed plan, prioritization of these factors, and making them consistent for effectiveness of Sammed plan can improve relations of government with citizens and vice versa. This study investigates the factors which influence the effectiveness of Sammed plan from the perspective of participants in Zahedan, Iran. The data collected through a questionnaire and conducting interviews. Based on Analytic Hierarchy Process (AHP), 384 were selected. The results of the data analysis showed that the first criterion which refers to people satisfactions of public services was given the highest priority and the criterion of creating suitable ground for interaction was given the lowest priority as key factors for effectiveness of implementation of Sammed plan. The people satisfactions of public services have high priority and it was located in the first level. This result indicates the considerable importance of interaction with citizens and e-service quality. It also necessitates providing high reliability services and great comfort for citizens. These would become possible through communication with people and having strong ties with them.
\end{abstract}

(C)AIMI Journals

\section{Introduction}

Development of the e-government system is based on the improvement of computer science and the expansion of Internet technology. Over the past few decades, we perceived 
remarkable developments in Information Technology (IT) and computer networks, namely IPV6 and distribution systems. E-government has been overshadowed by implementation of some factors, including pervasive food security, health and treatment issues, education, salary, security and having self-esteem in a relationship.

Regarding e-government and considering previous studies, two important players, namely citizens and government are differentiated. It is argued that if e-government is beneficial for both groups, in that case it can be successful (Srivastava, 2011). Information and communication technology plays a significant role in facilitation of state communication. In a similar vein, adopting information and communication technology is considered as a way for establishing communication between them. It is imperative to state that using information and communication technology in government will lead to an interaction between government and citizens and government performance of daily functions and operational duties. In order to accomplish this goal, it demands sharing knowledge and information for successful management of delivering state services to citizens (Chun, Luna-Rayes, \& SandovalAlmazán, 2012).

Executing e-government leads to development in intra-organizational process, achieving efficiency, and more appropriate public services, efficient management and processes development (Irani, Elliam, \& Jackson, 2007). Earlier studies demonstrated that between 60 to 80 per cent of projects in the field of e-government were not successful for some reasons (Heeks, 2006). This failure reveals some factors such as economic losses, missed opportunities for increasing effectiveness, lack of access to strategic purposeful results, dissatisfaction of the clients, and weakening the attempt. Moreover, this failure might include delays in presenting services, costs inflation, improper performance, and missing resources (Sultan, AlArfaj, \& AlKutbi, 2012).

In addition, previous studies show that citizens of most countries are not satisfied with the services of e-government (Irani, Weerakkody, Kamal, \& Hindi, 2011). Research conducted to date in the field of e-government underscore the fact that the quality of services is not examined in respect to satisfying the demands of citizens. Thus, the importance of service qualities in performing e-government and association of government with citizens have become one of the most considerable concerns of e-government in recent years (Alanezi, Kamil, \& Basri, 2010).

However, application and development of e-government necessitates special proficiencies and strategies. These are necessary not only for prioritizing the processes, but also it is of 
great importance in recognizing the effective electronic capabilities of the government. In addition, any research of e-government entails constructive feedback and creative ideas from citizens and dissatisfied people in order to master the challenges and basic modifications; besides, it provides success in e-government (Irani, Weerakkody, Kamal, \& Hindi, 2011).

Without doubt, it can be argued that in Iran, like other developing nations, responding to the high amount of problems and needs of society with current software and hardware installations is not possible. Inconsistency in construction and inaccurate mechanism in administrations have been contributed to delay in fulfilling people’s general needs. Actually, large amount of request, distributing of records in various administrative levels, redoing, delay in accessing the registered requests of the people, absence of well-known references in administrative levels, uncertain accessible ways for people to express their needs, poor performance of civil servants due to lack of an appropriate manner, inadequacy of feedback for organizing systematically, difficulty of people with rules and regulations, existence of some inappropriate expectations, and unreliable response to people's troubles necessitate it to establish a system in order to deal with these problems. Considering the large number of people's requests in the time of provincial travels of the government, shortage of a mechanized and affective system for responding to people's demands became clear and led to emersion of electronic base of communication among people Sammed government in the ninth government under the executive deputy of the president in order to completely supervise overall processes of inspection of people's demands and extend general satisfaction. For better realization of this goal, it seems necessary to carry out some efficient research about effective factors in implementation of this system.

For services of e-government, citizens are treated as clients or customers. One of the efficient factors of information system and services practiced by beneficiaries is quality. Egovernment aims to develop capability of state systems, enhance accountability, and improve quality of presenting services by providing new services for citizens (Saha, Nath, \& SalehiSangari, 2012). Factors such as IT and modern communication are considered as solutions for problems associated with dissatisfaction about e-government performance (Kim \& Grant, 2010). These efforts are made to heighten comfort, make citizens familiar with situation and provide access to IT and communication, and also familiarize them with the key role of the Internet in personal life, especially in commercial parts (Ebrahim \& Irani, 2005). This could be recognized when the relation between citizens is noticed significant and beliefs of citizens 
of presenting services can be computable in order to expand the services of e-government (Irani, Elliam, \& Jackson, 2007).

In the same way as other countries, developing countries are also looking for expanding their state services and developing citizens' contribution to public organizations with the help of practical plans of IT and communication in administrative organizations. This investment is justified when we launch a full potential of e-government. Improving the quality of state services, realizing the benefits of using IT and communication in administrative organizations are considered to be the final goals of e-government (Shareef, Archer, Sharen, \& Kumar, 2010).

In the same line of the argument, web sites which are designed to check out the complaints from the government, do not perfectly guide citizens in sending on-line complaints and in preventing their confusion when cooperating with other components of the site (Najar, AlSukhni, \& Aghakhani, 2010).

In addition, one of the crucial subjects that planning authorities are working on is how to reach the informative and communicative society. It is imperative to state that the information revolution has created a new perception of life that affects different aspects of both personal and social life. Nowadays, governments are struggling to use new information and communicative technology and make some changes in their ruling ways in such a way that implement their accountability mission in the least time with best quality and lowest cost.

\section{E-government and Sammed Plan}

Sammed is a system recording all the letters, complaints, requests, and people reports via various communication channels such as letter, telephone, Internet, and message. Besides, after the initial investigation, it transfers them to the relevant systems and receives the investigated results. Also, reporting and macro investigation of systems performance is possible based on people desires and appropriate results. By performing this plan, the government can deal with the requests and case reports of people and also can have a macro image of the performance of various systems at national and provincial level and can use it in selection and change of positions and responsibilities in new government.

After investigation of the models which refer to implementation of e-government and the development and improvement of e-government, we can assess the effective key factors in Sammed plan implementation. A summary of some models is that the e-government implementation model divide the implementation factors of e-government into technical, 
organizational, social, and political sectors and some indices are considered for these dimensions (Weerakkody et al., 2012); nine-stage model of e-government improvement and development are taken into account (Zarei, Ghapanchi, \& Sattary, 2008); and model of key factors in taking e-government by citizens are crucial points. This model is shown in Figure 1 (Shareef, Archer, Sharan, \& Kumar, 2010).

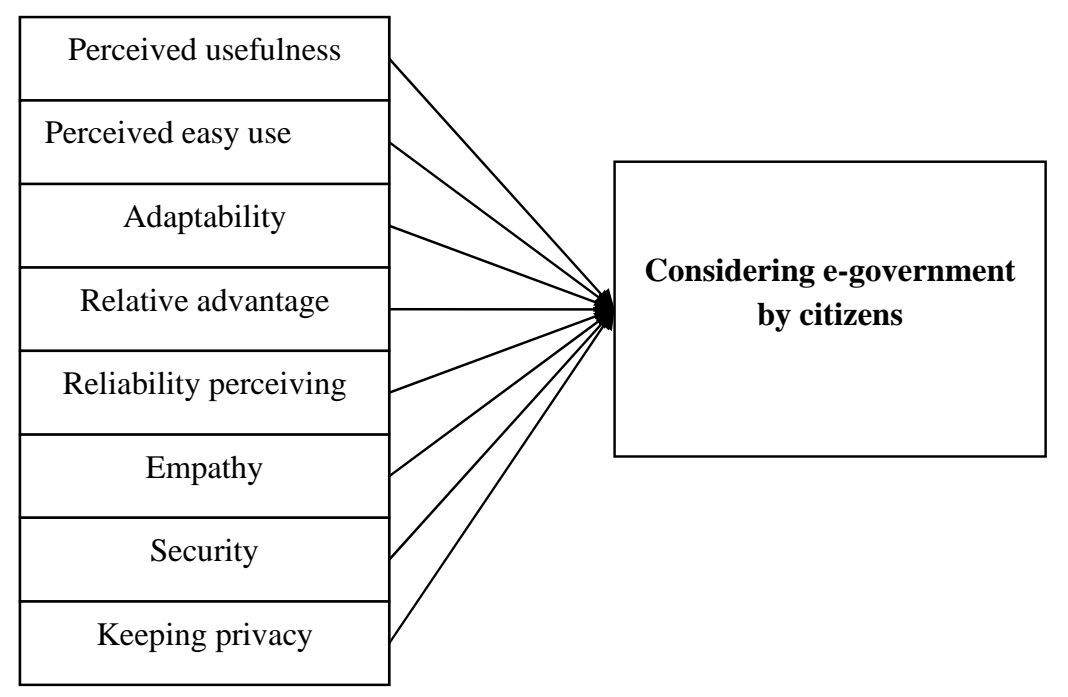

Figure 1. Key factors model of considering e-government by citizens (Adopted from Shareef, Archer, Sharan, \& Kumar, 2010)

\section{The Evaluation Model of Public Value of E-government}

Karunasena and Deng (2012) presented a model to evaluate public value of services of egovernment which is shown in Figure 2. 


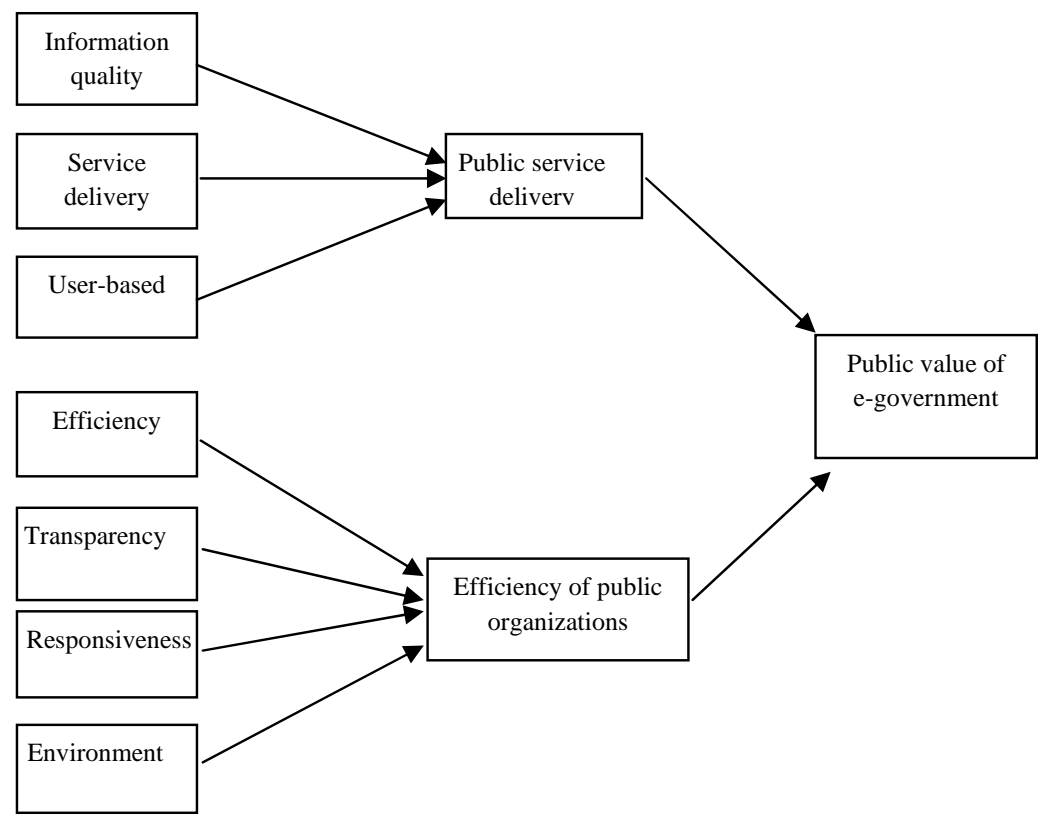

Figure 2. Evaluation model of public value of e-government (Adopted from Karunasena \& Deng, 2012)

Information quality is estimated according to the citizens' perception about existing information value and it is considered to measure accuracy, timeliness, and consistency. The government applies e-government plans to increase effectiveness of public services. Public values of e-government can be measured by perception of citizens about the total value of reciprocal trading and real time of interaction between government and users. User-based public service delivery focuses on citizen centered e-government services. In sum, the efficiency of state organizations is a key factor of public values measured by e-government and by organizational efficiency, transparency, responsiveness, and environment sustainability (Karunasena \& Deng, 2012).

\section{The Model of Service Quality Improvement via Managerial-Operational-Technical Dimensions}

Hsieh (2012) presented Managerial-Operational-Technical (MOT) dimensions for service quality improvement. 


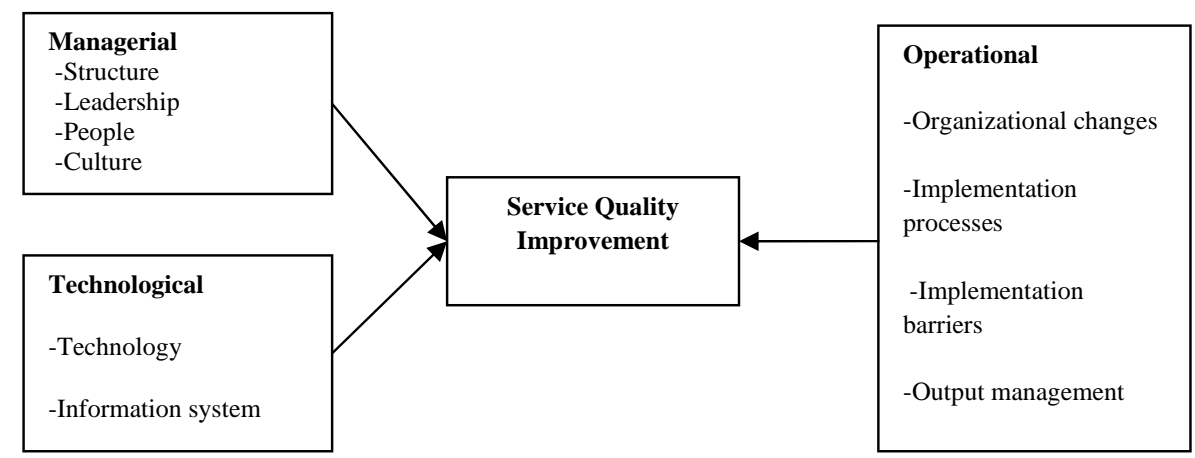

Figure 3. Service quality improvement model by MOT (Adopted from Hsien, 2012)

In his view, managerial dimension refers to required infrastructures for quality improvement plans. This dimension deals with the question whether structure or some strategies are taken to improve general quality and organizational leadership. Operational dimension relates to the process of quality improvement. Implementation of operational dimension includes the resources of quality improvement and support and utilization of them in order to control the work and enhance the quality of services. Technical dimension focuses on skills, techniques, and information systems for continuous quality improvement.

\section{Theoretical Model of Study}

It is imperative to state that most of the researchers conducted studies regarding the relevant factors of taking services of e-government. The present study is based on previous studies, public values of e-government services, purpose of citizens in using e-government services, services quality improvement model via dealing with the complaints, strategic factors model, relevant variables of e-government services quality, and citizens satisfaction of e-government services in governor center of Zahedan.

According to the goals of the model and theoretical findings, main elements of the study regarding citizens' intention to use e-government services and also considering effectiveness concepts, the following model is suggested. 


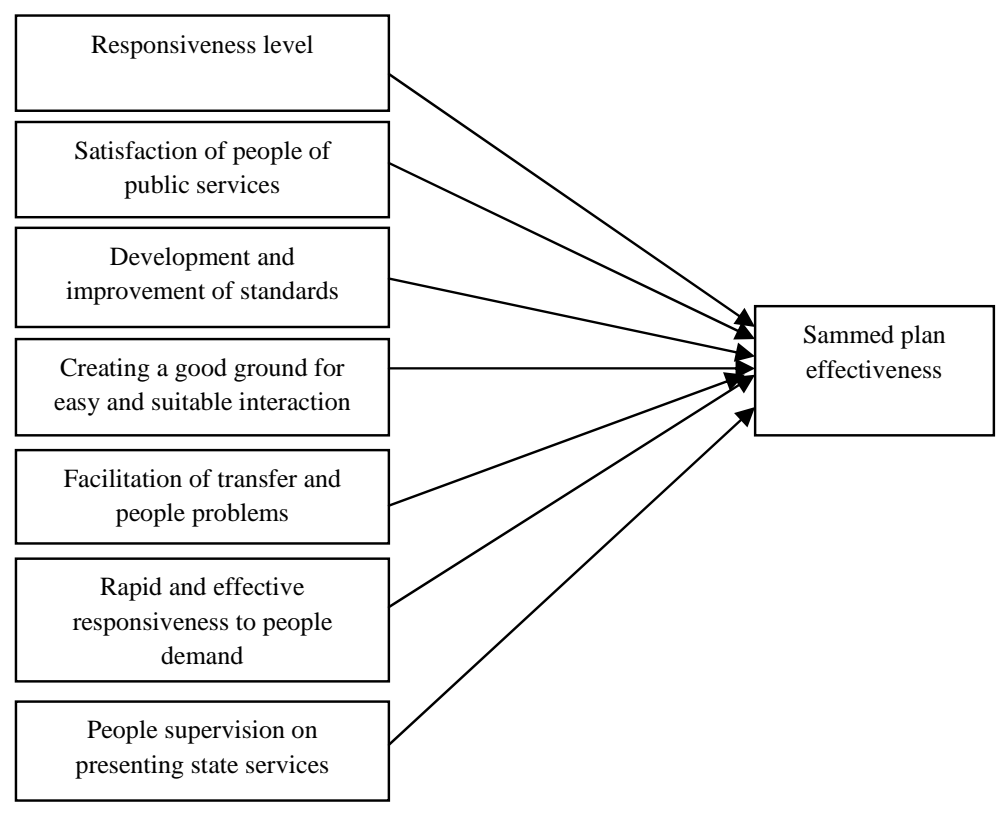

Figure 4. Proposed model of study

\section{Key Factors in Implementing Sammed}

There are a number of factors which are argued to exercise influence on efficiency of Sammed, including people satisfaction with public services which is emotional reaction of citizens or service receivers as the result of the gap between expected services and received services (Santouridis \& Trivellas, 2010); the development and improvement of standards that is a process intended to create a consistent growth and improvement in all parts of a process or processes and the standards are based on extension ranges, namely factory, corporative (community), national, regional and international (Al Thunibat, Zin, \& Sahari, 2011); purpose of acceptable ground with good facilities for easy interaction with citizens is providing the conditions in which the relationship between government and citizens is done easier and with fewer problems (Al-Hujran, 2012); in fact, facilitation in transfer and people problems is a positive form of feedback and it is a tool for more interaction with the recipients of services and audiences of organizations that acts as a process to attract their attention to the services provided by organization; giving rapid response to people demand is a concept that relates to government responsibility which aims to achieve citizens' satisfaction (Aloudat \& Michael, 2013); and people supervision on the presentation of state services that is a state in which citizens can investigate the form and presentation of state services (Alrazooqi \& Silva, 2010). 


\section{Hypotheses}

Based on the studies conducted to date and the perceived gap in this field of study, the following research hypotheses were formulated:

$\mathrm{H}_{0}$ : Responsiveness level, people satisfaction with public services, development and improvement of standards, creating a good ground for easy interaction, rapid responsiveness, effective dealing with the people demand, and people supervision on presenting state services are key factors in implementation of Sammed plan in Zahedan.

$\mathrm{H}_{1}$ : Prioritization of key factors in implementation of Sammed plan is different.

$\mathrm{H}_{2}$ : Periodization of sub-criteria of key factors is different in implementation of Sammed plan.

\section{Method}

This study is descriptive and field study which examines the identification and prioritization of key factors in implementation of Sammed plan in Zahedan. The identification of effective factors in implementation of Sammed plan is investigated by conducted researches about the implementation of Sammed plan and the interview with the experts in establishing this plan. Identified criteria are prioritized according to people's view in Zahedan. To collect data, a questionnaire consisting of 25 items was used. To check the validity of the questionnaire we asked a panel of the researchers to read the questionnaire and give any feedback regarding the clarity and linguistic validity of the items of the questionnaire. In addition, Expert Choice software is used in data analysis.

\section{Participants}

In the present study, people of Zahedan constitute the population of the study. Having considered the population of the study, 384 participants were randomly selected through employing Cochran's formula and the data was collected by distributing questionnaire among them. 


\section{The Design of Study Model}

Formulating decision tree hierarchy in hierarchy analysis process is the key factor and there shouldn't be any contradiction with basic theories regarding the relevant decision. After accessing the investigated results, it can be argued that the investigation of existing articles in Internet and interviewing with some of the experts in this field, the designed hierarchy, and the effectiveness of Sammed plan are in the first level. In the second level, the key criteria for implementation of Sammed plan are responsiveness, people satisfaction with public services, development and improvement of standards, creating suitable ground for easy interaction, rapid responsiveness and effective dealing with people demand, and people supervision on presenting state services. In the third level, there are sub-criteria of these main criteria. The tree hierarchy of prioritization of key factors for implementation of Sammed plan is shown in Figure 5.

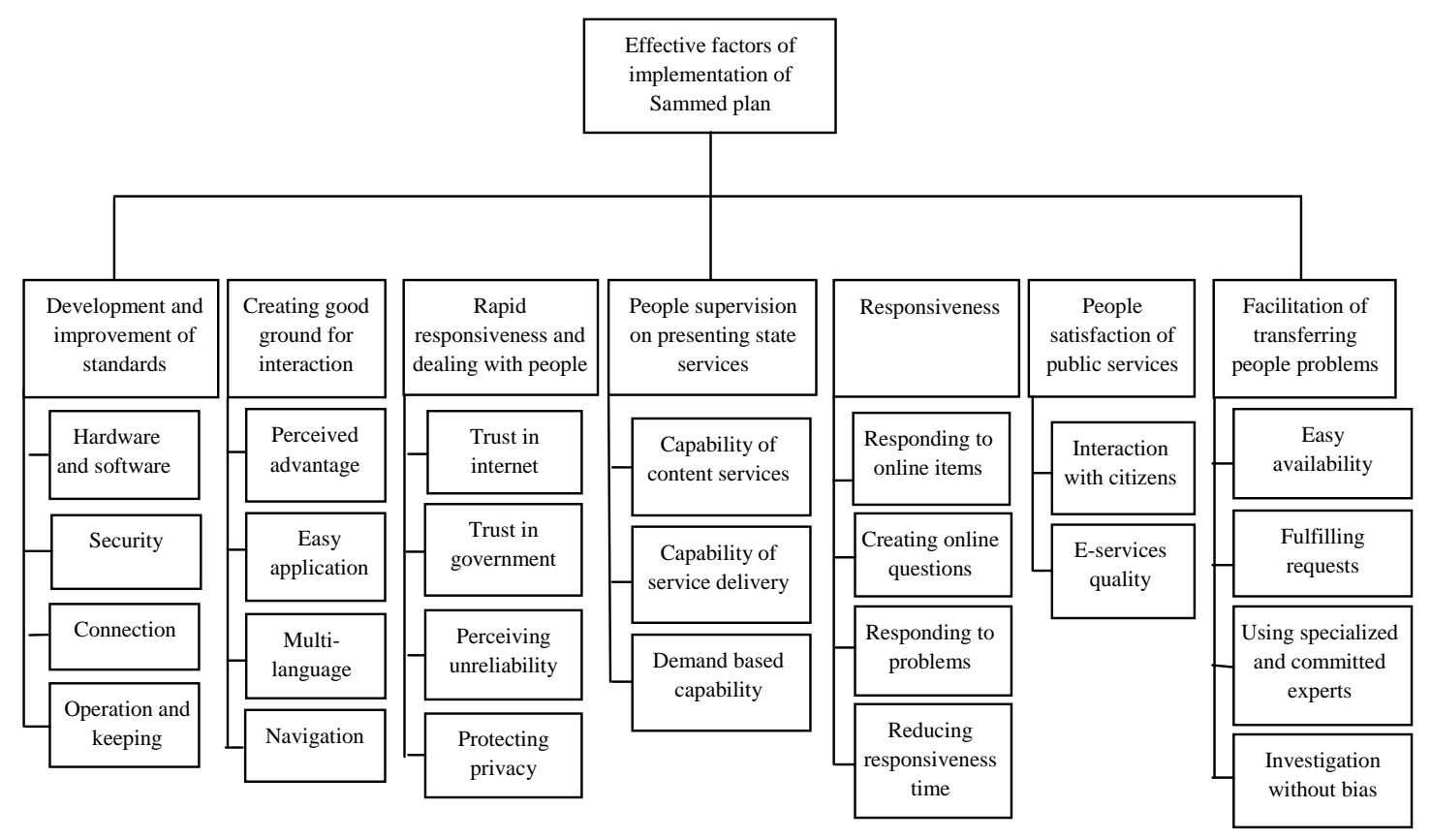

Figure 5. The hierarchy tree of key criteria and sub-criteria in implementation of Sammed plan

\section{Results}

After collection, extraction, and classification of data, the information analysis was performed. At first, the mean and mean ranks using SPSS software were calculated for all key factors in effectiveness of Sammed plan. After assessing the results, using ideas of experts in field of technology, and also applying hierarchy analysis process technique, the collected data was analyzed to support or reject the hypotheses. 
Table 1, considering view of respondents, presents the mean and mean rank of effective factors on effectiveness of Sammed.

Table 1

The Mean and Mean Rank of Effective Factors on Effectiveness of Sammed Plan

\begin{tabular}{lll}
\hline Mean rank & Mean & Variables \\
\hline 3.98 & 3.66 & People satisfaction of public services \\
3.69 & 3.43 & Development and improvement of standards \\
3.37 & 3.22 & Responsiveness level \\
2.89 & 3.29 & People supervision on presenting the services \\
2.78 & 3.06 & Facilitation of transferring people problems \\
2.75 & 3.00 & Rapid responsiveness and effective dealing with the people demands \\
2.34 & 2.82 & Creating suitable ground for easy and suitable interaction \\
\hline
\end{tabular}

Data was obtained through distributed questionnaires among people of Zahedan. According to Table 1, people satisfactions with public services and development and improvement of standards have major roles in effectiveness of Sammed plan. Also, they can create a good ground for easy interaction which indicates the mean of 2.82 and it has the minor role in effectiveness of Sammed plan. Based on the above findings, the survey of experts was considered and their answers were prioritized by AHP and Expert Choice software.

With respect to the first hypothesis, it was observed that seven factors of responsiveness, people satisfaction of public services, development and improvement of standards, creating a good ground for easy interaction, rapid responsiveness and effective dealing with people demand and people supervision on presenting state services are main factors in effectiveness of Sammed plan. The results are shown in Table 1. As inconsistency rate of pairwise comparison matrix of these criteria are 0.04 and inconsistency rate of model was totally 0.03 , these factors are consistent and reliable; so, the first hypothesis is supported.

Table 2

Relative and Final Weight of Main Effective Criteria for Implementation of Sammed Plan

\begin{tabular}{lcc}
\hline \multicolumn{1}{c}{ Criterion } & Final Weight & Relative Weight \\
\hline Development and improvement of standards & 0.26 & 0.26 \\
Creating a good ground for interaction & 0.02 & 0.02 \\
Rapid responsiveness and dealing with people demand & 0.04 & 0.04 \\
People supervision on presenting state services & 0.07 & 0.07 \\
Responsiveness level & 0.11 & 0.11 \\
Satisfaction of people of public services & 0.41 & 0.41 \\
Facilitation in transferring people problems & 0.06 & 0.06 \\
\hline
\end{tabular}


Having considered the second hypothesis, prioritization of key factors for implementation of Sammed plan is different. Ranking key factors for implementation of Sammed plan extracted by Expert Choice software is represented in Figure 6.

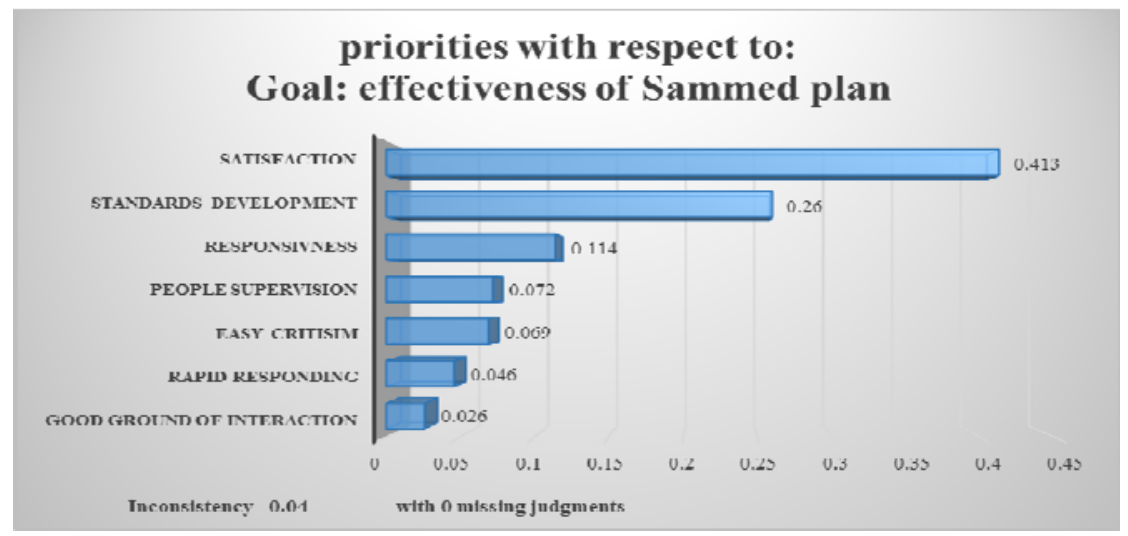

Figure 6. Relative weights of key factors for implementation of Sammed plan

As Table 2 and Figure 6 exhibit, the main effective criteria in effectiveness of Sammed plan have different priorities and as inconsistency rate was less than 0.1 , the model was consistent and reliable; so, the second hypothesis is supported. According to the results obtained through the questionnaire and regarding the view of people in Zahedan, final weight of seven main criteria in effectiveness of Sammed plan in the second level of decision tree hierarchy is demonstrated in this way: People satisfaction of public services (0.41), developing and improving standards (0.26), responsiveness level (0.11), people satisfaction of state services presenting (0.07), easy transfer of people problems (0.06), rapid responsiveness and dealing with people demand (0.04), and creating suitable ground for interaction (0.02).

As it is represented, according to the people of Zahedan who used Sammed system only once, three factors of people satisfaction with public services, developing and improvement of standards, and responsiveness are more important in comparison with other factors and averagely have $77.8 \%$ of effectiveness of Sammed plan in Zahedan.

With respect to the third hypothesis, prioritization of the sub-criteria of key factors for implementation of Sammed plan is different. Expert Choice software is applied to prioritize the main factors of sub-criteria in the third level of hierarchy and the results of relative and final weights and their rank are given in Table 3. 
Table 3

The Relative and Final Weights and Group and Final Rank of Sub Criteria

\begin{tabular}{|c|c|c|c|c|c|}
\hline $\begin{array}{l}\text { Total } \\
\text { rank }\end{array}$ & $\begin{array}{l}\text { Rank in } \\
\text { group }\end{array}$ & $\begin{array}{c}\text { Final } \\
\text { weight }\end{array}$ & $\begin{array}{c}\text { Relative } \\
\text { weight }\end{array}$ & Criterion & Group \\
\hline 1 & 1 & 0.36 & 0.88 & Quality of e-services & \multirow{2}{*}{ People satisfaction of public services } \\
\hline 6 & 2 & 0.04 & 0.11 & Interaction with citizens & \\
\hline 2 & 1 & 0.14 & 0.56 & Security & \multirow{4}{*}{$\begin{array}{l}\text { Development and improvement of } \\
\text { standards }\end{array}$} \\
\hline 4 & 2 & 0.05 & 0.22 & Software and hardware & \\
\hline 7 & 3 & 0.03 & 0.14 & Connection & \\
\hline 11 & 4 & 0.01 & .06 & Keeping operation & \\
\hline 3 & 1 & 0.06 & 0.59 & Reduction of response time & \multirow{4}{*}{ Responsiveness } \\
\hline 9 & 2 & 0.02 & 0.25 & Responding the problems & \\
\hline 16 & 3 & 0.01 & 0.09 & Responding the on-line items & \\
\hline 19 & 4 & 0.00 & 0.05 & Creating on-line questions & \\
\hline 5 & 1 & 0.47 & 0.66 & Capability of service delivery & \multirow{3}{*}{$\begin{array}{l}\text { The people supervision on presenting } \\
\text { state services }\end{array}$} \\
\hline 12 & 2 & 0.01 & 0.24 & Capability of content services & \\
\hline 20 & 3 & 0.006 & 0.08 & Demand-based capability & \\
\hline 8 & 1 & 0.03 & 0.54 & Easy access & \multirow{4}{*}{ Easy transfer of people problems } \\
\hline 13 & 2 & 0.01 & 0.24 & Fulfilling the requests & \\
\hline 17 & 3 & 0.008 & .12 & Investigation without bias & \\
\hline 22 & 4 & 0.008 & 0.07 & Using specialized and committed forces & \\
\hline 10 & 1 & 0.02 & .59 & Protecting privacy & \multirow{4}{*}{$\begin{array}{l}\text { Rapid responding and dealing with } \\
\text { people demand }\end{array}$} \\
\hline 15 & 2 & 0.12 & 0.25 & Trust in internet & \\
\hline 21 & 3 & 0.003 & .09 & Trust in government & \\
\hline 24 & 4 & 0.003 & 0.05 & Perceiving unreliability & \\
\hline 14 & 1 & 0.01 & 0.53 & Easy use & \multirow{4}{*}{ Creating suitable ground for interaction } \\
\hline 18 & 2 & 0.008 & 0.29 & Perceived advantage & \\
\hline 23 & 3 & 0.003 & 0.10 & Multi-lingual support & \\
\hline 25 & 4 & 0.002 & 0.06 & Navigation & \\
\hline
\end{tabular}

As Table 3 and Figure 7 clearly indicate, among 25 criteria in the third level of hierarchy, 8 sub- criteria, including quality of e-services (0.36), security (0.14), reduced responding time (0.06), hardware and software (0.05), the capability of service delivery (0.04), interaction with citizens (0.04), connection (0.03), and easy access (0.03) were of great importance in terms of the users of Sammed plan in Zahedan. These mentioned criteria in the third level of decision tree hierarchy had $81 \%$ of effectiveness for implementing Sammed plan. Also, people satisfaction of public services constitutes $40 \%$ of total effectiveness for implementation of Sammed plan. 


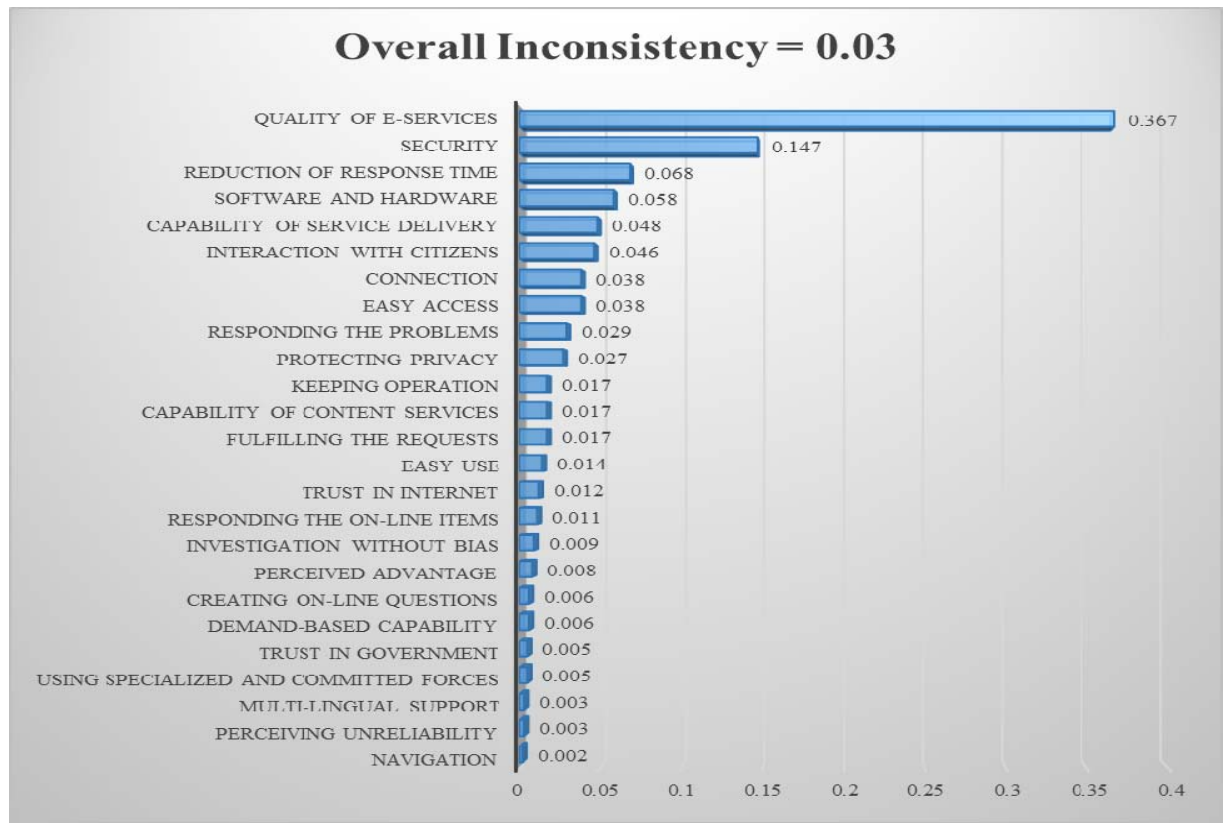

Figure 7. The chart of final ranking of sub criteria of effective key factors for implementation of Sammed plan

\section{Discussion and Conclusion}

In brief, 32 effective criteria and sub-criteria for implementation of Sammed plan was identified and listed. Then, using identified criteria and sub criteria, the questionnaire was designed. The results of the study showed that importance (final weight) of effective criteria on effectiveness of Sammed was very different as some criteria such as satisfaction of public services, development and improvement of standards and responsiveness form more than 90\% of effectiveness of Sammed plan in Zahedan. The government should improve quality of e-services, for example it can increase the system security, apply the related information, improve system efficiency, and interact with citizens. To do this, it can have contact information to associate with people and have friendly relations with citizens. The government should protect citizens' privacy and design a system that nobody can have availability to personal documents of citizens.

Accommodating infrastructures for new bandwidth, advancement of infrastructures for existing bandwidth, government policies to sustain and lead the innovative programs in order to develop the information and communicate technology, fundamental need for organizations for collecting data and their analyses for producing shared systems and infrastructures, and offering measuring tools in all parts for clear understanding of the citizen's demands and their skills are considered to be effective factors in developing the index of the expansion and improvement of standards in Sammed plan. 
Improving and promoting the index of providing a suitable area for easy and suitable interaction in Sammed plan includes frequent and regular control of website pages and being insured of their correct function, not using big pictures in the website, and operating the same navigation tool in all pages which states that tools in all pages must be in the same place and frame, because if the links suddenly appear in the pages, the users will get exhausted. Also, it requires providing a link for returning to home page from all pages. Because users may have entered the site through other pages and they may want to have accessibility to home page. Receptiveness and expressiveness of the menus and the possibility of accessing website sections directly from the home page are also demonstrated.

There are a number of factors which are argued to exercise influence on improving and promoting the index of people's satisfaction from public services in Sammed plan, including a reliable and genuine internet connection as a medium used in electronic communications, preparing educational files on the website with attention to the security and mechanism for preserving personal privacy, an increase in link popularity which is based on the number of actual entering links, presenting services with high accuracy and more accessibility to citizens through enhancing communication with them, and producing information and statistics relating to people's satisfaction from services.

In order to improve and promote the index of people's supervision over presenting services in Sammed plan some items, namely up-to-dating the current data on the site, performing services in conformity with user's demands, promotion of adoptability and effectiveness in expanding services such as governmental procedures and downloadable forms, development of transparency in state services to decrease their deviation, and providing accurate information, such as up-to-date, reliable, accurate, comprehensive, and creative information have crucial effects.

There exist a number of factors which are argued to have important roles in improvement and promotion of the index of the accountability level in Sammed plan, including creating an open environment in order to send and register the citizen's views, emphasizing the perspective of tolerance and accepting criticism in governmental organizations for responding appropriately to citizens' demands, preparing educational and on job training courses for civil servants in order to facilitate and enhance their communication with citizens, the available services of the web must be stated, and the feedback in responding to citizens changes fast.

For enhancing and developing the index of improvement and promotion of fast and functional response to people's demands in Sammed plan, some factors are considered to be 
important, including taking integration into account and not generating and sending data by third parties, acceleration and promotion in searching user's demands, user's control which means the choice of choosing how to browse the web and it includes the probability of managing the order of access to information (critical), the probability of managing interaction with the website (motivational), the probability of managing the complexities related to accessing the information (motivational), including frequently asked questions on your website: FAQ is a conventional method to answer the questions that users usually might ask when they use the website and it will prevent the users from uncertainty, proficiency and capability of civil servants to deliver and expand valuable services to customers, politeness and kindness of civil servants consists of civility, politeness, respectfulness, and kindness of the personnel in charge of contacts, namely receptionists and telephone operators.

For enhancing and developing the index of acceleration in conveying people's difficulties and troubles in Sammed plan, some items such as prompting answer to citizens' difficulties, assigning the follow-up codes of complaints, preparing a simple, online, and an obvious way of contact between people and government, and also studying and welcoming citizens' suggestions, criticisms, and opinions are suggested. Besides, some other factors can also exercise influence, including preparing high speed internet with reasonable cost for citizens, so they can do all their activities from home, preparing a pleasing and user-friendly port and website, providing education of computer and internet courses in elementary and guidance schools and developing courses of electronic for all citizens, offering practical and complete information on scientific sites of the Iran port in order to encourage citizens to use them more, preparing and designing options and links in the website to provide online help for users of the services of e-government, and increasing belief and confidence of citizens towards using services of e-government instead of using tradition and face to face techniques.

Today, e-government is observed as a principle in recognition of degree of underdevelopment of countries and worldwide. Hence, advancement of management and enhancement of preparing government services to citizens in electronic form have been taken into consideration. Thus, for the future researches the items including examining the above mentioned variables, longitudinal or continued research in different time periods for examining the quality of presented electronic services from state administrations and assurance of the expansion trend of this services, and studying and investigation of the subject of this research at the national level in order to analyze it among different cities and areas are suggested. 


\section{Reference}

Alanezi, M. A., Kamil. A., \& Basri, S. (2010). A proposed instrument dimensions for measuring e-government service quality. International Journal of V- and E-service, 3(4), 1-18.

Al-Hujran, O. (2012). Toward the utilization of m-Government services in developing countries: A qualitative investigation. International Journal of Business and Social Science, 3(5), 155-160.

Aloudat, A., \& Michael, K. (2013). Towards a conceptual model of user acceptance of location-based emergency services. International Journal of Ambient Computing and Intelligence, 5(2), 17-34.

Alrazooqi, M., \& Silva, R. (2010). An m-government solution proposal for Dubai Government. Paper presented at the Ninth WSEAS International Conference of Telecommunications and Informatics, Catania, Italy.

Al Thunibat, A., Zin, N.A.M., \& Sahari, N. (2011). Mobile government user requirements model. Journal of E-Governance, 34(2), 10-11.

Chun, S. A., Luna-Reyes, L. F., \& Sandoval-Almazán, R. (2012). Transforming government: People, Process and Policy. Collaborative E- government, 6(1), 5-12.

Ebrahim, Z., \& Irani, Z. (2005). E-government adoption: Architecture and barriers. Business Process Management Journal, 11(5), 589-611.

Heeks, R. (2006). Implementing and managing e-government: An international text. London: Sage Publications.

Hsieh, S.Y. (2012). Using complaints to enhance quality improvement: Developing an analytical tool. International Journal of Health Care Quality Assurance, 25(5), 453-461.

Irani, Z., Elliman, T., \& Jackson, P. (2007). Electronic transformation of government in the UK: A research agenda. European Journal of Information Systems, 16(4), 327-335.

Irani, Z., Weerakkody, V.,Kamal, M., \& Hindi, N. M. (2011). An analysis of methodologies utilised in e-government research: A user satisfaction perspective. Journal of Enterprise Information Management, 25(3), 298-313.

Karunasena, K., \& Deng, H. (2012). Critical factors for evaluating the public value of e-government in Sri Lanka. Government Information Quarterly, 29(1), 76-84.

Kim, D.Y., \& Grant, G. (2010). E-government maturity model using the capability maturity model integration. Journal of Systems and Information Technology, 12(3), 230-244.

Kim, S. E., \& Lehto, X. Y. (2012). The voice of tourists with mobility disabilities: Insights from online customer complaint websites. International Journal of Contemporary Hospitality Management, 24(3), 451-476.

Lee, H., Irani, Z., Osman, I. H., Balci, A., Ozkan, S., \& Medeni, T. D. (2008). Research note: Toward a reference process model for citizen-oriented evaluation of e-government services. Transforming Government: People, Process and Policy, 2(4), 297-310.

Najar, A. S., Al-Sukhni, H. A., \& Aghakhani, N. (2010). The application of service-oriented architecture in e-complaint system. Paper presented at the Second International Conference on Communication Software and Networks (ICCSN), (IEEE), Singapore.

Saha, P., Nath. A.K., \& Salehi-Sangari, E. (2012). Evaluation of government e-tax websites: An information quality and system quality approach. Transforming Government: People, Process and Policy, 6(3), 300-321.

Santouridis, I., \& Trivellas, P. (2010). Investigating the impact of service quality and customer satisfaction on customer loyalty in mobile telephony in Greece. The TQM Journal, 22(3), 330-343.

Shareef, M. A., Archer, N., Sharan, V., \& Kumar,V. (2010). Comparative e-government. USA, NY: Springer.

Srivastava, S. C. (2011). Is e-government providing the promised returns? A value framework for assessing e-government impact. Transforming Government: People, Process and Policy, 5(2), 107-113.

Sultan, A., AlArfaj, K.A., \& AlKutbi, G.A. (2012). Analytic hierarchy process for the success of e-government. Business Strategy Series, 13(6), 295-306.

Weerakkody, V., El-Haddadeh, R., Sabol, T, Ghoneim, A., \& Dzupka, P. (2012). E-government implementation strategies in developed and transition economies: A comparative study. International Journal of Information Management, 32(1), 6674.

Zarei, B., Ghapanchi, A., \& Sattary, B. (2008). Toward national e-government development models for developing countries: A nine-stage model. The International Information and Library Review, 40(3), 199-207. 